\title{
About Rough Neutrosophic Soft Sets Theory and Study Their Properties
}

\author{
Somen Debnath \\ Department of Mathematics, Tripura University, Agartala, India \\ Email address: \\ Somen008@rediffmail.com \\ To cite this article: \\ Somen Debnath. About Rough Neutrosophic Soft Sets Theory and Study Their Properties. Science Journal of Applied Mathematics and \\ Statistics. Vol. 7, No. 6, 2019, pp. 95-102. doi: 10.11648/j.sjams.20190706.11
}

Received: May 13, 2019; Accepted: October 4, 2019; Published: October 28, 2019

\begin{abstract}
Earlier fuzzy set, vague set, intuitionistic fuzzy set, L-fuzzy set etc are used as a mathematical tools for solving problems based on uncertainties or ambiguous in nature. But due to more complexity involves in problems exist in nature, traditional tools are unable to handle those in a systematic manner. So we need a tool which is more flexible to handle those problems. Which leads to the invention of soft set which was introduced by Molodtsov in 1999. Soft set (SS) theory is a mathematical tool deals with parametric data which are imprecise in nature. Ithis a generalization of fuzzy set theory. On the other hand Rough set (RS) theory and Neutrosophic set (NS) theory both rising as a powerful tool to handle these uncertain, incomplete, inconsistent and imprecise information in an effective manner. Actually Neutrosophic set is a generalization of intuitionistic fuzzy set. Sometimes it is not possible to handle all sorts of uncertain problems with a single mathematical tool. Fusion of two or more mathematical tools give rise to a new mathematical concept which gives an idea how to solve such type of problems in a more sophisticated ways. Which leads to the introduction of fuzzy soft set, rough soft set, intuitionistic fuzzy soft set, soft rough set etc. Neutrosophic soft set (NSS) was established by combining the concept of Soft set and Neutrosophic set. In this paper, using the concept of Rough set and Neutrosophic soft set a new concept known as Rough neutrosophic soft set (RNSS) is developed. Some properties and operations on them are introduced.
\end{abstract}

Keywords: Rough Set, Neutrosophic Set, Neutrosophic Soft Set

\section{Introduction}

In 1965 [1] L. A. Zadeh introduced the concept of fuzzy set which is termed as an extension of classical set or crisp set in which every element has a degree of membership. It is the most successful theoretical approach to vagueness. Unlike classical set theory, fuzzy set theory is described with an aid of membership function where the membership value of every element belongs to the unit interval $[0,1]$ so that it can be used in wide range of domains. Many mathematicians and researchers worked tirelessly on fuzzy set theory in different areas and able to extend this concept by developing some other theories such as vague set [2], L-fuzzy set [3], Rough set [4], i ntuitionistic fuzzy set [5], interval-valued fuzzy set [6], interval-valued intuitionistic fuzzy set [7] etc.

But all these theories have their own limitations and it is due to the lack of parametrization in a data. That's why soft set theory was introduced by Molodtsov [8] in 1999 to handle parametric data so that we can express the uncertain problems inmore generalized form. It has several applications in many fields like economics, engineering, medical sciences etc. In that period soft set was progressing more rapidly which leadsto the introduction of fuzzy soft set [9], intuitionistic fuzzy soft set [10], interval-valued fuzzy soft set [11], interval valued intuitionistic fuzzy soft set [12], rough soft set [13] etc.

In 1982, another mathematical tool which is known as rough set was introduced by computer scientist Z. Pawlak [4]. There are two basic elements in rough set theory, crisp set and equivalence relation, which constitute the mathematical basis of rough set. Upper and lower approximation operators are based on equivalence relation. It is a powerful tool to deal with incompleteness. It gives information of hidden data.

F. Smarandache [14] introduced the concept of neutrosophic set which is a generalization of intuitionistic fuzzy set. It is described by three functions: a membership function, indetermining function and a non membership function and they 
are independently related to each other. It is a mathematical tool for handling problems involving imprecise, indeterminacy and inconsistent data. Combining neutrosophic set with soft sets, neutrosophic soft set [15] is introduced by P. K. Maji.

Neutrosophic soft set and rough sets are two different terms, none contradict the other. The main objective of this study is to introduce a new hybridstructure called rough neutrosophic soft sets. The significance of introducing hybrid set structure is that thecomputation technique based on any one of these structure alone will not always yield the best results but a fusion of two or more of them can often give the better results.

\section{Preliminaries}

In this section we recall some basic definations and examples which are relevant to this work.

Definition 2.1 [8]:

Let $U$ be an initial universe and $E$ be a set of parameters. Let $P(U)$ denotes the power set of $U$ and $A \subseteq E$. Then the $\operatorname{pair}(F, A)$ is called a soft set over $U$ where $F$ is a mapping given by $F: A \rightarrow P(U)$.

Example 2.1.1

Suppose that $U=\left\{h_{1}, h_{2}, h_{3}, h_{4}, h_{5}, h_{6}, h_{7}\right\}$ is a univer se consisting of seven houses and $A=\left\{e_{1}, e_{2}, e_{3}, e_{4}\right\} \subseteq E$

is a set of parameters considered by the decision makers

where $e_{1}, e_{2}, e_{3}$ and $e_{4}$ represent the parameters 'beautiful', 'modern', 'cheap', 'in green surroundings' respectively.

Now, we consider a soft set $(F, A)$ which describes the'attractiveness of the house' that $\mathrm{Mr}$. $\mathrm{X}$ is going to buy. In this case, to define the soft set $(F, A)$ means to point out beautiful houses, modern houses and so on. Consider the mapping $F$ given by 'houses(.)' where (.) is to be filled by one of the parameters $e_{i} \in A$. For instance, $F\left(e_{1}\right)$ means 'houses (beautiful)'and the functional value is the set consisting of all the beautiful houses in $U$.

Let

$$
\begin{gathered}
F\left(e_{1}\right)=\left\{h_{5}, h_{7}\right\} \\
F\left(e_{2}\right)=\left\{h_{1}, h_{4}, h_{6}, h_{7}\right\} \\
F\left(e_{3}\right)=\left\{h_{1}, h_{3}\right\} \\
F\left(e_{4}\right)=\left\{h_{2}, h_{4}, h_{5}\right\} .
\end{gathered}
$$

Tabular representation of the soft $\operatorname{set}(F, A)$ is given by

Table 1. Soft set $(F, A)$.

\begin{tabular}{llllllll}
\hline & $\boldsymbol{h}_{\mathbf{1}}$ & $\boldsymbol{h}_{\mathbf{2}}$ & $\boldsymbol{h}_{\mathbf{3}}$ & $\boldsymbol{h}_{\mathbf{4}}$ & $\boldsymbol{h}_{\mathbf{5}}$ & $\boldsymbol{h}_{\mathbf{6}}$ & $\boldsymbol{h}_{\mathbf{7}}$ \\
\hline$e_{1}$ & 0 & 0 & 0 & 0 & 1 & 0 & 1 \\
$e_{2}$ & 1 & 0 & 0 & 1 & 0 & 1 & 1 \\
$e_{3}$ & 1 & 0 & 1 & 0 & 0 & 0 & 0 \\
$e_{4}$ & 0 & 1 & 0 & 1 & 1 & 0 & 0 \\
\hline
\end{tabular}

Definition 2.2 [14]:

Let $X$ be an universe of discourse, with a generic elementin $X$ denoted by $\mathrm{x}$, the neutrosophic set (NS) is an object having the form

$$
A=\left\{\left\langle x: \mu_{A}(x), v_{A}(x), \omega_{A}(x)\right\rangle, x \in X\right\},
$$

Where the functions $\mu, v, \omega: X \rightarrow]^{-} 0,1^{+}[$define respectively the degree of membership (or Truth), the degree of indeterminacy, and the degree of non-membership (orFalsehood) of the element $x \in X$ to the set $A$ with the condition $^{-} 0 \leq \mu_{A}(x)+v_{A}(x)+\omega_{A}(x) \leq 3^{+}$.

From a philosophical point of view, the neutrosophic set takes the value from real standard or non-standard sub sets of ]$^{-} 0,1^{+}[\text {. So, instead of }]^{-} 0,1^{+}[$we need to take the interval $[0,1]$ for technical applications, because $]^{-} 0,1^{+}[$will be difficult to apply in the real applications such as in scientific and engineering problems.

Example 2.2.1

Assume that the universe of discourse $U=\left\{x_{1}, x_{2}, x_{3}\right\}$, where $x_{1}$ characterizes the capability, $x_{2}$ characterizes the trustworthiness and $x_{3}$ indicates the prices of the objects. It may be further assumed that the values of $x_{1}, x_{2}$ and $x_{3}$ are in $[0,1]$ and they are obtained from some questionnaires of some experts. The experts may impose their opinion in three components viz. the degree of goodness, the degree of indeter minacy and that of poorness to explain the characteristics of the objects. Suppose $A$ is a neutrosophic set (NS) of $U$, such that

$$
A=\left\{\left\langle x_{1},(0.3,0.5,0.6)\right\rangle,\left\langle x_{2},(0.3,0.2,0.3)\right\rangle,\left\langle x_{3},(0.3,0.5,0.6)\right\rangle\right\},
$$

Where the degree of goodness of capability is 0.3 , degree of indeterminacy of capability is 0.5 and degree of falsity of capability is 0.6 etc.

Definition 2.3 [13]:

Let $E$ and $U$ be the set of parameters and the universe set respectively. Let $R$ be an equivalence relation on $U$. If $F_{E}$ is a soft set then we define two soft sets

$\vec{F}: E \rightarrow P(U)$ and $\overleftarrow{F}: E \rightarrow P(U)$ as follows :

$$
\vec{F}(e)={ }_{R}^{*}(F(e)) \text { and } \overleftarrow{F}(e)=R_{*}(F(e))
$$

We call the soft sets $\vec{F}_{E}$ and $\overleftarrow{F}_{E}$, the upper soft set and the lower soft set respectively.

Proposition 2.4 [13]

If $F_{E}$ is a soft set over the universe $U$ then $\overleftarrow{F}_{E} \subseteq F_{E} \subseteq \vec{F}_{E}$

Definition 2.5 [4]:

Let $U$ be any non-empty set. Suppose $R$ be an equivalence 
relation over $U$. For any non-null subset $X$ of $U$, the sets

$$
A_{1}(x)=\left\{x:[x]_{R} \subseteq X\right\} \text { and } A_{2}(x)=\left\{x:[x]_{R} \cap X \neq \varnothing\right\}
$$

are called the lower approximation and upper approximation, respectively of $X$, where the pair $S=(U, R)$ is called an approximation space. This equivalent relation $R$ is called indiscernibility relation.

The pair $A(x)=\left(A_{1}(x), A_{2}(x)\right)$ is called the rough set of $X$. Here $[x]_{R}$ denotes the equivalence class of $R$ containing $x$.

Definition 2.6 [4]:

Let $A=\left(A_{1}, A_{2}\right)$ and $B=\left(B_{1}, B_{2}\right)$ be two rough sets in the approximation space $S=(U, R)$. Then,

$$
\begin{aligned}
& A \cup B=\left(A_{1} \cup B_{1}, A_{2} \cup B_{2}\right), \\
& A \cap B=\left(A_{1} \cap B_{1}, A_{2} \cap B_{2}\right), \\
& \mathrm{A} \subseteq B \text { if } A \cap B=A, \\
& \square A=\left\{U-A_{2}, U-A_{1}\right\}
\end{aligned}
$$

Definition 2.7 [15]:

Let $U$ be an initial universe set and $E$ be a set of parameters. Consider $A \subset E$. Let $P(U)$ denotes the set of all neutrosophic sets of $U$. The collection $(F, A)$ is termed to be the neutrosophic soft set over $U$, where $F$ is a mapping given by $F: A \rightarrow P(U)$.

Example 2.7.1

Let $U$ be the set of houses under consideration and $E$ be the set of parameters. Each parameter is a neutrosophic word or sentence involvingneutrosophic words.

Consider $E=\{$ beautiful, wooden, costly, very costly, moderate, green surroundings, in good repair, in bad repair, cheap, expensive . In this case, to define a neutrosophic soft set means to point out beautiful houses, wooden houses, houses in the green surroundings and so on. Suppose that, there are five houses in the universe $U$ given by, $U=$ $\left\{h_{1}, h_{2}, h_{3}, h_{4}, h_{5}\right\}$ and the set of parameters $A=\left\{e_{1}, \mathrm{e}_{2}, \mathrm{e}_{3}, \mathrm{e}_{4}\right\}$, where, $e_{1}$ stands for the parameter 'beautiful', $e_{2}$ stands for the parameter 'wooden', $e_{3}$ stands for the parameter 'costly'and the parameter $\mathrm{e}_{4}$ stands for 'moderate'.

Suppose that

$$
\begin{aligned}
& F(\text { beautiful })=\left\{\left\langle h_{1}, 0.5,0.6,0.3\right\rangle,\left\langle h_{2}, 0.4,0.7,0.6\right\rangle,\left\langle h_{3}, 0.6,0.2,0.3\right\rangle,\left\langle h_{4}, 0.7,0.3,0.2\right\rangle,\left\langle h_{5}, 0.8,0.2,0.3\right\rangle\right\}, \\
& F(\text { wooden })=\left\{\left\langle h_{1}, 0.6,0.3,0.5\right\rangle,\left\langle h_{2}, 0.7,0.4,0.3\right\rangle,\left\langle h_{3}, 0.8,0.1,0.2\right\rangle,\left\langle h_{4}, 0.7,0.1,0.3\right\rangle,\left\langle h_{5}, 0.8,0.3,0.6\right\rangle\right\}, \\
& F(\cos \text { tly })=\left\{\left\langle h_{1}, 0.7,0.4,0.3\right\rangle,\left\langle h_{2}, 0.6,0.7,0.2\right\rangle,\left\langle h_{3}, 0.7,0.2,0.5\right\rangle,\left\langle h_{4}, 0.5,0.2,0.6\right\rangle,\left\langle h_{5}, 0.7,0.3,0.4\right\rangle\right\}, \\
& F(\bmod \text { erate })=\left\{\left\langle h_{1}, 0.8,0.6,0.4\right\rangle,\left\langle h_{2}, 0.7,0.9,0.6\right\rangle,\left\langle h_{3}, 0.7,0.6,0.4\right\rangle,\left\langle h_{4}, 0.7,0.8,0.6\right\rangle,\left\langle h_{5}, 0.9,0.5,0.7\right\rangle\right\} .
\end{aligned}
$$

The neutrosophic soft set (NSS) $(F, E)$ is a parametrized family $\left\{F\left(e_{i}\right), i=1,2, \ldots . .10\right\}$ of all neutrosophic sets of $U$ and describes a collection of approximation of an object. The mapping $F$ here is 'houses(.)', where $\operatorname{dot}($.$) is to be filled up$

$$
\left\{\left\langle h_{1}, 0.5,0.6,0.3\right\rangle,\left\langle h_{2}, 0.4,0.7,0.6\right\rangle,\left\langle h_{3}, 0.6,0.2,0.3\right\rangle,\left\langle h_{4}, 0.7,0.3,0.2\right\rangle,\left\langle h_{5}, 0.8,0.2,0.3\right\rangle\right\} .
$$

Thus we can view the neutrosophic soft set $(\mathrm{NSS})(F, A)$ as a collection of approximation as below:

$$
(F, A)=\left\{\begin{array}{l}
\text { beautiful houses }=\left\{\left\langle h_{1}, 0.5,0.6,0.3\right\rangle,\left\langle h_{2}, 0.4,0.7,0.6\right\rangle,\left\langle h_{3}, 0.6,0.2,0.3\right\rangle,\left\langle h_{4}, 0.7,0.3,0.2\right\rangle,\left\langle h_{5}, 0.8,0.2,0.3\right\rangle\right\}, \\
\text { wooden houses }=\left\{\left\langle h_{1}, 0.6,0.3,0.5\right\rangle,\left\langle h_{2}, 0.7,0.4,0.3\right\rangle,\left\langle h_{3}, 0.8,0.1,0.2\right\rangle,\left\langle h_{4}, 0.7,0.1,0.3\right\rangle,\left\langle h_{5}, 0.8,0.3,0.6\right\rangle\right\}, \\
\cos \text { tly houses }=\left\{\left\langle h_{1}, 0.7,0.4,0.3\right\rangle,\left\langle h_{2}, 0.6,0.7,0.2\right\rangle,\left\langle h_{3}, 0.7,0.2,0.5\right\rangle,\left\langle h_{4}, 0.5,0.2,0.6\right\rangle,\left\langle h_{5}, 0.7,0.3,0.4\right\rangle\right\}, \\
\text { mod erate houses }=\left\{\left\langle h_{1}, 0.8,0.6,0.4\right\rangle,\left\langle h_{2}, 0.7,0.9,0.6\right\rangle,\left\langle h_{3}, 0.7,0.6,0.4\right\rangle,\left\langle h_{4}, 0.7,0.8,0.6\right\rangle,\left\langle h_{5}, 0.9,0.5,0.7\right\rangle\right\}
\end{array}\right\},
$$

Where each approximation has two parts: (i) a predicate p, and (ii) an approximate value-set v (or simply to be called value-set v).

The tabular representation of the neutrosophic soft set $(F, A)$ is as follows: 


$$
\left[\begin{array}{ccccc}
\multicolumn{5}{c}{\text { Table 2. Neutrosophic Soft Set }} \\
U & \text { beautiful } & \text { wooden } & \text { costly } & \text { moderate } \\
h_{1} & (0.5,0.6,0.3) & (0.6,0.3,0.5) & (0.7,0.4,0.3) & (0.8,0.6,0.4) \\
h_{2} & (0.4,0.7,0.6) & (0.7,0.4,0.3) & (0.6,0.7,0.2) & (0.7,0.9,0.6) \\
h_{3} & (0.6,0.2,0.3) & (0.8,0.1,0.2) & (0.7,0.2,0.5) & (0.7,0.6,0.4) \\
h_{4} & (0.7,0.3,0.2) & (0.7,0.1,0.3) & (0.5,0.2,0.6) & (0.7,0.8,0.6) \\
h_{5} & (0.8,0.2,0.3) & (0.8,0.3,0.6) & (0.7,0.3,0.4) & (0.9,0.5,0.7)
\end{array}\right]
$$

It is useful for computer storage.

\section{Definition $2.8[15]$ :}

Let $(F, A)$ and $(G, B)$ be two neutrosophic soft sets over the common universe $U .(F, A)$ is said to be neutrosophic soft subset of $(G, B)$ if $A \subseteq B \quad, \quad$ and $T_{F_{E}}(x) \leq T_{G_{E}}(x), I_{F_{E}}(x) \leq I_{G_{E}}(x), F_{F_{E}}(x) \geq F_{G_{E}}(x), \forall e \in A$, $x \in U$

Definition 2.9 [15]:

Let $(F, A)$ and $(G, B)$ be two neutrosophic soft sets over the common universe $U$.

Then their union $(F, A) \cup(G, B)=(K, C)$ and the truthmembership, indeterminacy membership and falsity membership of $(K, C)$ are as follows:

$$
\begin{aligned}
T_{K(e)}(m) & =T_{F(e)}(m), \text { if } e \in A-B \\
& =T_{G(e)}(m), \text { if } e \in B-A \\
& =\max \left(T_{F(e)}(m), T_{G(e)}(m)\right), \text { if } e \in A \cap B \\
I_{K(e)}(m) & =I_{F(e)}(m), \text { if } e \in A-B \\
& =I_{G(e)}(m), \text { if } e \in B-A \\
& =\frac{I_{F(e)}(m)+I_{G(e)}(m)}{2}, \text { if } e \in A \cap B \\
F_{K(e)}(m) & =F_{F(e)}(m), \text { if } e \in A-B \\
& =F_{G(e)}(m), \text { if } e \in B-A \\
& =\min \left(F_{F(e)}(m), F_{G(e)}(m)\right), \text { if } e \in A \cap B
\end{aligned}
$$

Let $(F, A)$ and $(G, B)$ be two neutrosophic soft sets over the common universe $U$.

Then their intersection $(F, A) \cap(G, B)=(K, C)$ and the truth membership, indeterminacy membership and falsity membership of $(K, C)$ are as follows:

$$
\begin{aligned}
& T_{K(e)}(m)=\min \left(T_{F(e)}(m), T_{G(e)}(m)\right) \\
& I_{K(e)}(m)=\frac{I_{F(e)}(m)+I_{G(e)}(m)}{2} \\
& F_{K(e)}(m)=\max \left(F_{F(e)}(m), F_{G(e)}(m)\right)
\end{aligned}
$$

\section{Rough Neutrosophic Soft Sets}

Here we introduce the concept of rough neutrosophic soft sets by combining both rough sets and neutrosophic soft sets and perform some operations viz. union, intersection, inclusion and equality over them.

Definition 3.1:

Let $U$ be a non-empty universe set, $E$ be a set of parameters and $R$ be an equivalence relation on $U$. Considering $A \subset E$. Let $P(U)$ denotes the set of all neutrosophic sets of $U$. The collection $(F, \mathrm{~A})$ is termed to be the neutrosophic soft set over $U$ where $F: A \rightarrow P(U)$ with membership function $\mu_{F}$, indeterminacy function $v_{F}$ and nonmembership function $\omega_{F}$. The lower and upper neutrosophic soft set approximation of $F$ in the approximation space $(U, R)$ denoted by $N_{*}(F)$ and $N^{*}(F)$ respectively and they are defined as follows:

Definition 2. 10 [15]:

$$
\begin{gathered}
N_{*}(F)=\left\{\left\{e_{i},\left\{\left\langle x, \mu_{N_{*}(F)}(x), v_{N_{*}(F)}(x), \omega_{N_{*}(F)}(x)\right)\right\}:[x]_{R} \subseteq X, x \in U\right\}\right\}, \\
N^{*}(F)=\left\{\left\{e_{i},\left\{\left\{x, \mu_{N^{*}(F)}(x), v_{N^{*}(F)}(x), \omega_{N^{*}(F)}(x)\right)\right\}:[x]_{R} \cap X \neq \varnothing, x \in U\right\}\right\}, \forall e_{i}, \\
\mu_{N_{*}(F)}(x)=\underset{y \in[x]_{R}}{\hat{\mu}_{F}} \mu_{F}(y), v_{N_{*}(F)}(x)=\underset{y \in[x]_{R}}{\hat{N}} v_{F}(y), \omega_{N_{*}(F)}(x)=\underset{y \in[x]_{R}}{\vee} \omega_{F}(y)
\end{gathered}
$$


and $\mu_{N^{*}(F)}(x)=\underset{y \in[x]_{R}}{\vee} \mu_{F}(y), v_{N^{*}(F)}(x)=\underset{y \in[x]_{R}}{\vee} v_{F}(y)$, $\omega_{N^{*}(F)}(x)=\underset{y \in[x]_{R}}{\wedge} \omega_{F}(y)$

provided $\quad 0 \leq \mu_{N^{*}(F)}(x)+v_{N^{*}(F)}(x)+\omega_{N^{*}(F)}(x) \leq 3 \quad$ and $0 \leq \mu_{N_{*}(F)}(x)+v_{N_{*}(F)}(x)+\omega_{N_{*}(F)}(x) \leq 3$

where the symbols $\wedge$ and $\vee$ used to denote minimum and maximum operators respectivel-y and the pair $\left(N_{*}(F), N^{*}(F)\right)$ is called the rough neutrosophic soft set in $(U, R)$.

If $N_{*}(F)=N^{*}(F)$ then $\mu_{N_{*}(F)}=\mu_{N^{*}(F)}, \nu_{N_{*}(F)}=v_{N^{*}(F)}$ and $\omega_{N_{*}(F)}=\omega_{N^{*}(F)}$. So it is no more a rough neutrosophic soft set i.e. it is called a definable neutrosophic soft set.

Example 3.1.1

Let $U=\left\{h_{1}, h_{2}, h_{3}, h_{4}, h_{5}\right\}$ be a set of houses under consideration, $X \subset U$ where $X=\left\{h_{1}, h_{4}, h_{5}\right\}$ and $R$ be an equivalence relation and its partition of $U$ is,

$$
[x]_{R}=U / R=\left\{\left\{h_{1}, h_{4}\right\},\left\{h_{2}, h_{3}\right\},\left\{h_{5}\right\}\right\}
$$

Let $E$ be a set of parameter where $E=\left\{e_{1}, \mathrm{e}_{2}, \mathrm{e}_{3}, \mathrm{e}_{4}\right\}$. Then $(F, E)$ is called the neutrosophic soft set and $F: E \rightarrow P(U)$ where $P(U)$ denotes the set of all neutrosophic sets.

Now we consider the neutrosophic soft set as:

$$
N(F)=\left\{\begin{array}{l}
\left\{e_{1},\left\langle h_{1}, 0.5,0.6,0.3\right\rangle,\left\langle h_{2}, 0.4,0.7,0.6\right\rangle,\left\langle h_{3}, 0.6,0.2,0.3\right\rangle,\left\langle h_{4}, 0.7,0.3,0.2\right\rangle,\left\langle h_{5}, 0.8,0.2,0.3\right\rangle\right\}, \\
\left\{e_{2},\left\langle h_{1}, 0.6,0.3,0.5\right\rangle,\left\langle h_{2}, 0.7,0.4,0.3\right\rangle,\left\langle h_{3}, 0.8,0.1,0.2\right\rangle,\left\langle h_{4}, 0.7,0.1,0.3\right\rangle,\left\langle h_{5}, 0.8,0.3,0.6\right\rangle\right\}, \\
\left.\left\{e_{3},\left\langle h_{1}, 0.7,0.4,0.3\right\rangle,\left\langle h_{2}, 0.6,0.7,0.2\right\rangle,\left\langle h_{3}, 0.7,0.2,0.5\right\rangle,\left\langle h_{4}, 0.5,0.2,0.6\right\rangle,\left\langle h_{5}, 0.7,0.3,0.4\right\rangle\right\},\right\}, \\
\left\{e_{4},\left\langle h_{1}, 0.8,0.6,0.4\right\rangle,\left\langle h_{2}, 0.7,0.9,0.6\right\rangle,\left\langle h_{3}, 0.7,0.6,0.4\right\rangle,\left\langle h_{4}, 0.7,0.8,0.6\right\rangle,\left\langle h_{5}, 0.9,0.5,0.7\right\rangle\right\}
\end{array}\right\}
$$

Thus the lower and the upper rough neutrosophic soft set corresponding to $X$ is given by,

$$
N_{*}(F)=\left\{\begin{array}{l}
\left\{e_{1},\left\langle h_{1}, 0.5,0.3,0.3\right\rangle,\left\langle h_{4}, 0.5,0.3,0.3\right\rangle,\left\langle h_{5}, 0.8,0.2,0.3\right\rangle\right\}, \\
\left\{e_{2},\left\langle h_{1}, 0.6,0.1,0.5\right\rangle,\left\langle h_{4}, 0.6,0.1,0.5\right\rangle,\left\langle h_{5}, 0.8,0.3,0.6\right\rangle\right\}, \\
\left\{e_{3},\left\langle h_{1}, 0.5,0.2,0.6\right\rangle,\left\langle h_{4}, 0.5,0.2,0.6\right\rangle,\left\langle h_{5}, 0.7,0.3,0.4\right\rangle\right\}, \\
\left\{e_{4},\left\langle h_{1}, 0.7,0.6,0.6\right\rangle,\left\langle h_{4}, 0.7,0.6,0.6\right\rangle,\left\langle h_{5}, 0.9,0.5,0.7\right\rangle\right\}
\end{array}\right\},
$$

and

$$
N^{*}(F)=\left\{\begin{array}{l}
\left\{e_{1},\left\langle h_{1}, 0.7,0.6,0.2\right\rangle,\left\langle h_{4}, 0.7,0.6,0.2\right\rangle,\left\langle h_{5}, 0.8,0.2,0.3\right\rangle\right\}, \\
\left\{e_{2},\left\langle h_{1}, 0.7,0.3,0.3\right\rangle,\left\langle h_{4}, 0.7,0.3,0.3\right\rangle,\left\langle h_{5}, 0.8,0.3,0.6\right\rangle\right\}, \\
\left\{e_{3},\left\langle h_{1}, 0.7,0.4,0.3\right\rangle,\left\langle h_{4}, 0.7,0.4,0.3\right\rangle,\left\langle h_{5}, 0.7,0.3,0.4\right\rangle\right\}, \\
\left\{e_{4},\left\langle h_{1}, 0.8,0.8,0.4\right\rangle,\left\langle h_{4}, 0.8,0.8,0.4\right\rangle,\left\langle h_{5}, 0.9,0.5,0.7\right\rangle\right\}
\end{array}\right\},
$$

From the above results we can write $N_{*}(F) \neq N^{*}(F)$.

But we find some examples in real world where we can show that $N_{*}(F)=N^{*}(F)$. In those cases rough neutrosophic soft sets reduced as defina-ble neutrosophic soft set.

Definition 3.2:

If $N(F)=\left(N_{*}(F), N^{*}(F)\right)$ is a rough neutrosophic soft set in $(U, R)$, the rough complement of $N(F)$ is the rough neutrosophic

soft set denoted by
the complements of neutrosophic soft sets $N_{*}(F)$ and $N^{*}(F)$ respectively.

Then,

$$
N_{*}(F)^{c}=\left\{\left\{e_{i},\left\langle x, \omega_{N_{*}(F)}(x), 1-v_{N_{*}(F)}(x), \mu_{N_{*}(F)}(x)\right\rangle\right\}: x \in U\right\}
$$

and 


$$
N^{*}(F)^{c}=\left\{\left\{e_{i},\left\langle x, \omega_{N^{*}(F)}(x), 1-v_{N^{*}(F)}(x), \mu_{N^{*}(F)}(x)\right\rangle\right\}: x \in U\right\}
$$

Example 3.2.1

Reference to example 3.1.1, we have

$$
\begin{gathered}
N_{*}(F)^{c}=\left\{\begin{array}{l}
\left\{e_{1},\left\langle h_{1}, 0.3,0.7,0.5\right\rangle,\left\langle h_{4}, 0.3,0.7,0.5\right\rangle,\left\langle h_{1}, 0.3,0.8,0.8\right\rangle\right\}, \\
\left\{e_{2},\left\langle h_{1}, 0.5,0.9,0.6\right\rangle,\left\langle h_{4}, 0.5,0.9,0.6\right\rangle,\left\langle h_{5}, 0.6,0.7,0.8\right\rangle\right\}, \\
\left\{e_{3},\left\langle h_{1}, 0.6,0.8,0.5\right\rangle,\left\langle h_{4}, 0.6,0.8,0.5\right\rangle,\left\langle h_{5}, 0.4,0.7,0.7\right\rangle\right\}, \\
\left\{e_{4},\left\langle h_{1}, 0.6,0.4,0.7\right\rangle,\left\langle h_{4}, 0.6,0.4,0.7\right\rangle,\left\langle h_{5}, 0.7,0.5,0.9\right\rangle\right\}
\end{array}\right\} \\
N^{*}(F)^{c}=\left\{\begin{array}{l}
\left\{e_{1},\left\langle h_{1}, 0.2,0.4,0.7\right\rangle,\left\langle h_{4}, 0.2,0.4,0.7\right\rangle,\left\langle h_{5}, 0.3,0.8,0.8\right\rangle\right\}, \\
\left\{e_{2},\left\langle h_{1}, 0.3,0.7,0.7\right\rangle,\left\langle h_{4}, 0.3,0.7,0.7\right\rangle,\left\langle h_{5}, 0.6,0.7,0.8\right\rangle\right\}, \\
\left\{e_{3},\left\langle h_{1}, 0.3,0.6,0.7\right\rangle,\left\langle h_{4}, 0.3,0.6,0.7\right\rangle,\left\langle h_{5}, 0.4,0.7,0.7\right\rangle\right\}, \\
\left\{e_{4},\left\langle h_{1}, 0.4,0.2,0.8\right\rangle,\left\langle h_{4}, 0.4,0.2,0.8\right\rangle,\left\langle h_{5}, 0.7,0.5,0.9\right\rangle\right\}
\end{array}\right\}
\end{gathered}
$$

By the definition 2.8 it can be observed that,

$$
N^{*}(F)^{c} \subseteq N_{*}(F)^{c}
$$

But it is not true in general.

Definition 3.3:

If $N\left(F_{1}\right)$ and $N\left(F_{2}\right)$ are two rough neutrosophic soft sets of the neutrosophic soft sets $F_{1}$ and $F_{2}$ respectively in $U$, then we have the following results:
(i) $N\left(F_{1}\right)=N\left(F_{2}\right)$ iff $N_{*}\left(F_{1}\right)=N_{*}\left(F_{2}\right)$ and $N^{*}\left(F_{1}\right)=N^{*}\left(F_{2}\right)$
(ii) $N\left(F_{1}\right) \subseteq N\left(F_{2}\right)$ iff $N_{*}\left(F_{1}\right) \subseteq N_{*}\left(F_{2}\right)$ and $N^{*}\left(F_{1}\right) \subseteq N^{*}\left(F_{2}\right)$
(iii) $N\left(F_{1}\right) \cup N\left(F_{2}\right)=\left\langle N_{*}\left(F_{1}\right) \cup N_{*}\left(F_{2}\right), N^{*}\left(F_{1}\right) \cup N^{*}\left(F_{2}\right)\right\rangle$
(iv) $N\left(F_{1}\right) \cap N\left(F_{2}\right)=\left\langle N_{*}\left(F_{1}\right) \cap N_{*}\left(F_{2}\right), N^{*}\left(F_{1}\right) \cap N^{*}\left(F_{2}\right)\right\rangle$
(v) $N\left(F_{1}\right)+N\left(F_{2}\right)=\left\langle N_{*}\left(F_{1}\right)+N_{*}\left(F_{2}\right), N^{*}\left(F_{1}\right)+N^{*}\left(F_{2}\right)\right\rangle$
(vi) $N\left(F_{1}\right) \cdot N\left(F_{2}\right)=\left\langle N_{*}\left(F_{1}\right) \cdot N_{*}\left(F_{2}\right), N^{*}\left(F_{1}\right) \cdot N^{*}\left(F_{2}\right)\right\rangle$

Proposition 3.4

If $N, M, L$ are rough neutrosophic soft set in $(U, R)$, then the following propositions are straight forward:

(i) $\square N(\square N)=N$

(ii) $N \cup M=M \cup N, N \cap M=M \cap N$

(iii) $(N \cup M) \cup L=N \cup(M \cup L),(N \cap M) \cap L=N \cap(M \cap L)$

(iv) $(N \cup M) \cap L=(\mathrm{L} \cap M) \cup(N \cap L),(N \cap M) \cup L=(N \cup L) \cap(\mathrm{M} \cup L)$

Proposition 3.5 (De Morgan's Laws)

(i) $\square\left(N\left(F_{1}\right) \cup N\left(F_{2}\right)\right)=\left(\square N\left(F_{1}\right)\right) \cap\left(\square N\left(F_{2}\right)\right)$

(ii) $\square\left(N\left(F_{1}\right) \cap N\left(F_{2}\right)\right)=\left(\square N\left(F_{1}\right)\right) \cup\left(\square N\left(F_{2}\right)\right)$

Proof:

(i) $\square\left(N\left(F_{1}\right) \cup N\left(F_{2}\right)\right)=\square\left\langle\left\{N_{*}\left(F_{1}\right) \cup N_{*}\left(F_{2}\right)\right\},\left\{N^{*}\left(F_{1}\right) \cup N^{*}\left(F_{2}\right)\right\}\right\rangle$

$=\left\langle\square\left\{N_{*}\left(F_{1}\right) \cup N_{*}\left(F_{2}\right)\right\}, \square\left\{N^{*}\left(F_{1}\right) \cup N^{*}\left(F_{2}\right)\right\}\right\rangle$ 


$$
\begin{aligned}
& =\left\langle\left\{N_{*}\left(F_{1}\right) \cup N_{*}\left(F_{2}\right)\right\}^{c},\left\{N^{*}\left(F_{1}\right) \cup N^{*}\left(F_{2}\right)\right\}^{c}\right\rangle \\
& =\left\langle\square\left\{N_{*}\left(F_{1}\right) \cap N_{*}\left(F_{2}\right)\right\}, \square\left\{N^{*}\left(F_{1}\right) \cap N^{*}\left(F_{2}\right)\right\}\right\rangle \\
& =\left(\square N\left(F_{1}\right)\right) \cap\left(\square N\left(F_{2}\right)\right)
\end{aligned}
$$

(ii) Similar to the proof of (i)

Proposition 3.6

If $F_{1}$ and $F_{2}$ are two neutrosophic soft sets in $U$ such that $F_{1} \subseteq F_{2}$, then $N\left(F_{1}\right) \subseteq N\left(F_{2}\right)$

(i) $N\left(F_{1} \cup F_{2}\right) \supseteq N\left(F_{1}\right) \cup N\left(F_{2}\right)$

(ii) $N\left(F_{1} \cap F_{2}\right) \subseteq N\left(F_{1}\right) \cap N\left(F_{2}\right)$

Proof :

$$
\begin{aligned}
\mu_{N_{*}\left(F_{1} \cup F_{2}\right)}(x) & =\inf \left\{\mu_{\left(F_{1} \cup F_{2}\right)}(x): x \in X_{i}\right\} \\
& =\inf \left(\max \left\{\mu_{F_{1}}(x), \mu_{F_{2}}(x)\right\}: x \in X_{i}\right) \\
& \geq \max \left\{\inf \left\{\mu_{F_{1}}(x): x \in X_{i}\right\}, \inf \left\{\mu_{F_{2}}(x): x \in X_{i}\right\}\right\} \\
& =\max \left\{\mu_{N_{*}\left(F_{1}\right)}\left(x_{i}\right), \mu_{N_{*}\left(F_{2}\right)}\left(x_{i}\right)\right\} \\
& =\left(\mu_{N_{*}\left(F_{1}\right)} \cup \mu_{N_{*}\left(F_{2}\right)}\right)\left(x_{i}\right)
\end{aligned}
$$

Similarly,

Hence, $N\left(F_{1} \cup F_{2}\right) \supseteq N\left(F_{1}\right) \cup N\left(F_{2}\right)$

$$
\begin{aligned}
& v_{N_{*}\left(F_{1} \cup F_{2}\right)}(x) \geq\left(v_{N_{*}\left(F_{1}\right)} \cup v_{N_{*}\left(F_{2}\right)}\right)\left(x_{i}\right) \\
& \omega_{N_{*}\left(F_{1} \cup F_{2}\right)}(x) \leq\left(\omega_{N_{*}\left(F_{1}\right)} \cup \omega_{N_{*}\left(F_{2}\right)}\right)\left(x_{i}\right)
\end{aligned}
$$$$
\text { (ii) The proof of (ii) is similar to the proof of (i) }
$$$$
\text { Proposition } 3.7
$$

(i) $N_{*}(F)=\square N^{*}(\square F)$

(ii) $N^{*}(F)=\square N_{*}(\square F)$

Thus, $N_{*}\left(F_{1} \cup F_{2}\right) \supseteq N_{*}\left(F_{1}\right) \cup N_{*}\left(F_{2}\right)$

We can also see that

(iii) $N_{*}(F) \subseteq N^{*}(F)$

Proof:

$$
N^{*}\left(F_{1} \cup F_{2}\right) \supseteq N^{*}\left(F_{1}\right) \cup N^{*}\left(F_{2}\right)
$$

By definition,

$$
\begin{gathered}
F=\left\{e_{i},\left\{\left\langle x, \mu_{N(F)}(x), v_{N(F)}(x), \omega_{N(F)}(x)\right)\right\}: x \in X\right\} \\
\square F=\left\{e_{i},\left\{\left\langle x, \omega_{N(F)}(x), 1-v_{N(F)}(x), \mu_{N(F)}(x)\right)\right\}: x \in X\right\} \\
N^{*}(\square F)=\left\{e_{i},\left\{\left\{x, \omega_{N^{*}(F)}(x), 1-v_{N^{*}(F)}(x), \mu_{N^{*}(F)}(x)\right)\right\}:[x]_{R} \cap X \neq \varnothing, x \in U\right\} \\
\square N^{*}(\square F)=\left\{e_{i},\left\{\left\langle x, \mu_{N^{*}(F)}(x), 1-\left(1-v_{N^{*}(F)}(x)\right), \omega_{N^{*}(F)}(x), \mu_{N^{*}(F)}(x)\right)\right\}:[x]_{R} \subseteq X, x \in U\right\} \\
=N_{*}(F)
\end{gathered}
$$

(ii) The proof is similar to the proof of (i)

(iii) For any $y \in N_{*}(F)$, we have

$$
\begin{gathered}
\mu_{N_{*}(F)}(x)=\underset{y \in[x]_{R}}{\wedge} \mu_{F}(y) \leq \underset{y \in[x]_{R}}{\vee} \mu_{F}(y), \\
v_{N_{*}(F)}(x)=\underset{y \in[x]_{R}}{\vee} v_{F}(y) \leq \underset{y \in[x]_{R}}{\wedge_{F}} v_{F}(y)
\end{gathered}
$$

$$
\text { and } \omega_{N_{*}(F)}(x)=\underset{y \in[x]_{R}}{\vee} \omega_{F}(y) \geq \underset{y \in[x]_{R}}{\wedge} \omega_{F}(y)
$$

Thus, $N_{*}(F) \subseteq N^{*}(F)$

\section{Conclusion}

In this work we have introduced the notion of rough 
neutrosophic soft sets by using equivalence relation. We have also studied some basic operations on them and proved some properties. The new concept of rough neutrosophic soft sets is developedby using rough sets, soft sets and neutrosophic sets. Soft set theory mainly concerned with parametric data, while neutrosophic set theory deals with indeterminate and consistent information and rough set theory is with incompleteness. So rough neutrosophic soft sets can be utilized for dealing with parametrization, indeterminacy and incompleteness. So in future there is a scope of using the rough neutrosophic Soft set in various problems of uncertainties and get more vulnerable results.

\section{References}

[1] L. A. Zadeh, Fuzzy set, Information and Control, 8 (1965), 338-353.

[2] W. L. Gau, D. J. Buehrer, Vague sets, IEEE Trans. Systems, Man, and Cybernetics, 23 (1993), 610-614.

[3] J. Goguen, L-fuzzy sets, Journal of Mathematical Analysis and Applications, 18 (1967), 145-174.

[4] Z. Pawlak, Rough sets, International Journal of Computer and Information Sciences, 11 (1982) 341-356.

[5] K. Atanassov, Intuitionistic fuzzy sets, Fuzzy Sets and Systems, 20 (1986), 87-96.
[6] M. Gorzalczany, A method of inference in approximate reasoning based on interval valued fuzzy sets, Fuzzy Sets and Systems, 21 (1987), 1-17.

[7] K. Atanassov, G. Gargov, Interval valued intuitionistic fuzzy sets, Fuzzy Sets and Systems, 31 (1989), 343-349.

[8] D. Molodtsov, Soft set theory first results, Computers and Mathematics with Application, 37 (1999), 19-31.

[9] P. K. Maji, R. Biswas, A. R. Roy, Fuzzy Soft Sets, Journal of Fuzzy Mathematics, 9 (2001), 589-602.

[10] P. K. Maji, R. Biswas, A. R. Roy, Intuitionistic fuzzy soft sets, Journal of Fuzzy Mathematics, 12 (2004), 669-683.

[11] B. Chetia, P. K. Das, An application of interval valued fuzzy soft sets in medical diagnosis, International Journal of Contemporary Mathematical Sciences, 5 (2010), 1887-1894.

[12] Y. Jiang, Y. Tang, Q. Chen, H. Liu, J. Tung, Interval valued intuitionistic fuzzy soft sets and their properties, Computers andMathematics with Applications, 60 (2010), 906-918.

[13] K. Moinuddin, Rough soft sets, International Journal of Computational and Applied Mathematics, 12 (2017), 537-543.

[14] F. Smarandache, Neutrosophic set, International Journal of Pure and Applied Mathematics, 24 (2005), 287-297.

[15] P. K. Maji, Neutrosophic soft set, Annals of Fuzzy Mathematics and Informatics, 5 (2013), 157-168. 